\title{
THE PREDICTIVE VALUE OF POST-OPERATIVE INTRAOCULAR PRESSURES FOLLOWING TRABECULECTOMY
}

\author{
S. M. DOWNES, G. P. MISSON, H. S. JONES and E. C. O'NEILL \\ Birmingham
}

\begin{abstract}
SUMMARY
The value of post-operative intraocular pressure (IOP) in predicting the outcome of trabeculectomy was investigated in a retrospective study of single eyes of 203 Caucasian patients with uncomplicated chronic open angle glaucoma from the Birmingham and Midland Eye Hospital. Post-operative IOPs were recorded on day 1 , at 2 weeks, and at 3, 6, 12 and 24 months. Surgical failure, defined as an IOP of $21 \mathrm{mmHg}$ or above throughout the study period, occurred in 66 eyes by 24 months (32.5\% failure). Discriminant analysis for the first day post-operative IOP showed a reliability of prediction of success (RPS) and failure (RPF) of $76.4 \%$ and $74.4 \%$ respectively, with an accuracy of prediction of success (APS) and failure (APF) of $92.6 \%$ and $42.6 \%$. At 2 weeks, APS remained high $(90.3 \%)$ and APF increased with time $(63.2 \%)$. Certainty of success prediction at any stage is high and certainty of failure prediction becomes greater with time. In terms of IOP on the first post-operative day, 92.6\% of successes may be correctly predicted if the IOP $<17 \mathrm{mmHg}$ and $42.6 \%$ of failures may be predicted if the IOP $\geqslant 17 \mathrm{mmHg}$. This study suggests that identification of patients at risk of failure on the basis of IOP in the early post-operative period is possible and that closer follow-up and early medical or surgical intervention may be indicated.
\end{abstract}

The purpose of trabeculectomy ${ }^{1.2}$ in the management of glaucoma is to reduce intraocular pressure (IOP) on the assumption that a raised IOP leads to optic nerve damage. ${ }^{3}$ Surgical success of this procedure is therefore the reduction of IOP.

Several studies investigating the long-term results of trabeculectomy have identified putative risk factors for failure, including: high pre-operative IOP, pre-operative

Correspondence to: Miss Susan Melissa Downes, FRCOphth, Registrar in Ophthalmology, Birmingham and Midland Eye Hospital, Church Street, Birmingham B3 2NS, UK. topical medications, status of surgeon, procedure type, hyphaema, shallow anterior chamber, high post-operative IOP, and a flat bleb..$^{4-7}$ The aim of this study was to determine the prognostic significance of the early post-operative IOP, in terms of failure as defined by an untreated IOP $\geqslant 21 \mathrm{mmHg}$.

\section{MATERIALS AND METHODS}

A retrospective review of case notes of 203 patients undergoing trabeculectomy at the Birmingham and Midland Eye Hospital between January 1988 and December 1989 was undertaken. Only Caucasian patients with uncomplicated chronic open angle glaucoma were included. In all cases a standard trabeculectomy, based on the procedure described by Watson, ${ }^{2}$ was performed by senior staff and residents in training. Variations in technique were principally related to the location of the conjunctival flap. All cases were treated post-operatively with topical steroids (betamethasone or dexamethasone), antibiotics (chloramphenicol) or a combination (Maxitrol, Alcon) and mydriatics (cyclopentolate 1\% or atropine 1\%) until post-operative inflammation had subsided, usually after 4-6 weeks. Ocular hypotensives (topical and systemic) were discontinued in the post-operative period unless their reintroduction was required.

The following information was recorded: patient's age, sex and pre-operative ocular medications, date of surgery, surgeon seniority (Senior Registrar, Registrar, etc.), and details of the procedure. IOPs were recorded at first presentation, pre-operatively and then on the first day postoperatively, at 2 weeks, and at 3, 6, 12 and 24 months later. All IOPs were determined by Goldmann applanation tonometry.

If post-operative therapy was reintroduced, or further surgery carried out, the date of this was noted. Success was defined as a post-operative IOP consistently lower than $21 \mathrm{mmHg}$ without topical or systemic ocular hypoten- 
Table I. Summary statistics

\begin{tabular}{lcc}
\hline & Success & Failure \\
\hline Number & & \\
Sex & 137 & 66 \\
$\quad$ Male & 65 & 38 \\
Female & 72 & 28 \\
Age (yr) & & \\
Mean & 69.5 & 69.1 \\
SD & 10.8 & 8.75 \\
Range & $35-89$ & $39-86$ \\
Eye & & \\
Right & 73 & 39 \\
Left & 64 & 27 \\
Pre-operative IOP (mmHg) & & \\
Mean & 25.1 & 25.2 \\
SD & 6.60 & $16-46$ \\
Range & $14-44$ & \\
Minor operative complications & & 13 \\
Hyphaema & 35 & 5 \\
Shallow AC & 16 & 2 \\
Flat AC & 2 & Nil \\
Major operative complications & & \\
\hline A & & \\
\hline
\end{tabular}

$\mathrm{AC}$, anterior chamber.

sives. The introduction of medication, the need for surgery, or an IOP consistently at or above $21 \mathrm{mmHg}$ was classified as surgical failure. This criterion of failure is that adopted by previous studies. ${ }^{4}$

Statistical evaluation included construction of a Kaplan-Meier curve and logistic discriminant analysis of the post-operative data. The method of Kaplan and Meier ${ }^{8}$ determines outcome (e.g. of treatment) that takes into account irregular intervals of time between observations and incomplete data. The Kaplan-Meier curve is a plot of cumulative probability of outcome (in this case surgical success) with respect to time. Logistic discriminant analy$\operatorname{sis}^{9}$ is a statistical method of determining an equation that best discriminates between successes and failures at various times post-operatively. The equation so derived can then be used to give an estimate of probability of success at any post-operative time for any single subject.

\section{RESULTS}

Details of the study population are given in Table I.
Table II. Analysis of outcome of trabeculectomy with respect to time

\begin{tabular}{rrrccc}
\hline $\begin{array}{c}\text { Time } \\
\text { (days) }\end{array}$ & $\begin{array}{c}\text { Total } \\
\text { no. at } \\
\text { risk }\end{array}$ & Failures & $\begin{array}{c}\text { Probability } \\
\text { of failure }(\%)\end{array}$ & $\begin{array}{c}\text { Probability } \\
\text { of success }(\%)\end{array}$ & $\begin{array}{c}\text { Cumulative } \\
\text { probability } \\
\text { of success }(\%)\end{array}$ \\
\hline 1 & 203 & 17 & 8 & 92 & 92 \\
14 & 183 & 16 & 9 & 91 & 84 \\
30 & 163 & 10 & 6 & 94 & 79 \\
90 & 153 & 6 & 4 & 96 & 76 \\
180 & 142 & 9 & 6 & 94 & 71 \\
365 & 137 & 6 & 4 & 96 & 68 \\
730 & 114 & 2 & 2 & 98 & 67 \\
\hline
\end{tabular}

Of the 203 trabeculectomies performed, 66 (32.5\%) failed by the end of the second year. There were no significant differences in pre-operative features of the success or failure groups. All post-operative complications were minor, and comprised: hyphaema in 35 of 137 (25.5\%) in the success group and 13 of $66(19.7 \%)$ in the failure group; and the presence of a shallow anterior chamber in 16 of $137(11.7 \%)$ in the success group and 5 of $66(7.6 \%)$ in the failure group. In addition 2 flat anterior chambers that deepened spontaneously within 1 week were noted in both groups. There were no major complications such as malignant glaucoma, endophthalmitis or persistent flat anterior chambers. Results of survival analysis are shown in Table II and the plot of cumulative success against time (Fig. 1) indicates that cumulative success of trabeculectomy in this study falls from an initial $92 \%$ on the first post-operative day to $67 \%$ at the end of the study period.

The mean age of the group of patients classified as successes was 69.5 years (range $35-89$ years), with 65 men and 72 women. Those in the failure group had a mean age of 69.1 years (range 39-86 years), with 38 men and 28 women. Mean pre-operative IOP measured on the day of admission in the success group was $25.1 \mathrm{mmHg}$ (range $14-44 \mathrm{mmHg}$ ); that in the failure group was $25.2 \mathrm{mmHg}$ (range $16-46 \mathrm{mmHg}$ ). All cases had an IOP $>21 \mathrm{mmHg}$ recorded at some point in the pre-operative period.

For the first post-operative day, the logistic discriminant function predicts a failure if the IOP is $\geqslant 17 \mathrm{mmHg}$. The subsequent prediction of outcome depends on previous and present IOPs according to the probability functions presented in Table III. Also tabulated are the accuracy for outcome (success or failure) and the reliability of pre-

Table III. Results of logistic discriminant analysis ${ }^{\mathrm{a}}$

\begin{tabular}{|c|c|c|c|c|c|}
\hline Time interval & $\begin{array}{l}\text { Accuracy for } \\
\text { success } \\
(\%)\end{array}$ & $\begin{array}{l}\text { Accuracy for } \\
\text { failure } \\
(\%)\end{array}$ & $\begin{array}{l}\text { Reliability of } \\
\text { prediction for } \\
\text { success } \\
(\%)\end{array}$ & $\begin{array}{l}\text { Reliability of } \\
\text { prediction for } \\
\text { failure } \\
(\%)\end{array}$ & Probability function ${ }^{b}$ \\
\hline Day 1 & 92.6 & 42.6 & 76.4 & 74.4 & $\operatorname{Ln}(p / 1-p)=-2.359+(0.139 \times$ day $1 \mathrm{IOP})$ \\
\hline Week 2 & 90.3 & 63.2 & 82.9 & 76.8 & $\begin{aligned} \operatorname{Ln}(p / 1-p)= & -4.341+(0.091 \times \text { day } 1 \mathrm{IOP})+ \\
& (0.183 \times \text { week } 2 \text { IOP })\end{aligned}$ \\
\hline Month 1 & 88.2 & 75.8 & 87.5 & 76.9 & $\begin{array}{c}\operatorname{Ln}(p / 1-p)=-6.992+(0.088 \times \text { day } 1 \text { IOP })+ \\
(0.152 \times \text { week } 2 \text { IOP })+(0.205 \text { month1 IOP })\end{array}$ \\
\hline Month 3 & 93 & 77.4 & 89.5 & 84.2 & $\begin{array}{l}\operatorname{Ln}(p / 1-p)=-10.45+(0.125 \times \text { day } 1 \text { IOP })+ \\
(0.116 \times \text { week } 2 \text { IOP })+(0.419 \times \text { month3 IOP })\end{array}$ \\
\hline
\end{tabular}

\footnotetext{
${ }^{a}$ Terminology defined in text.
}

${ }^{\mathrm{b}}$ Where $p=\operatorname{prob}$ (failure). 


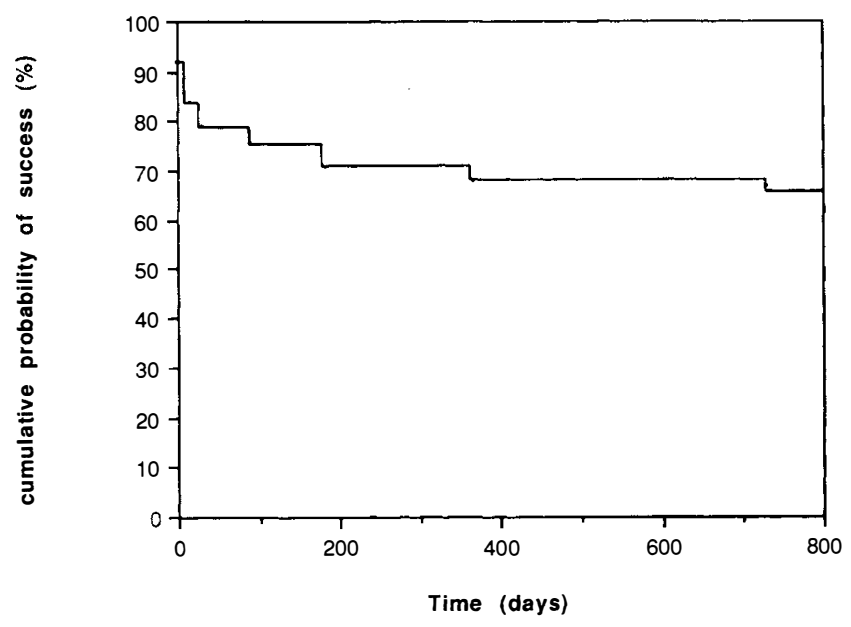

Fig. 1. Kaplan-Meier curve of cumulative probability of success against time.

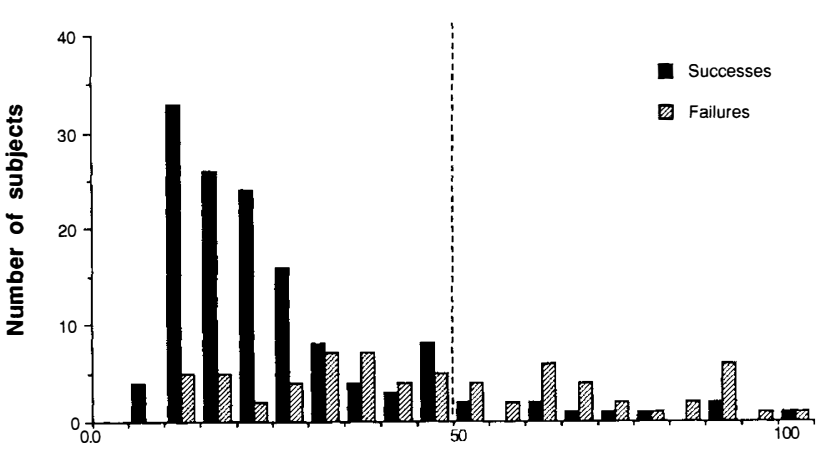

Predicted probability of failure (\%) Day 1

(a)

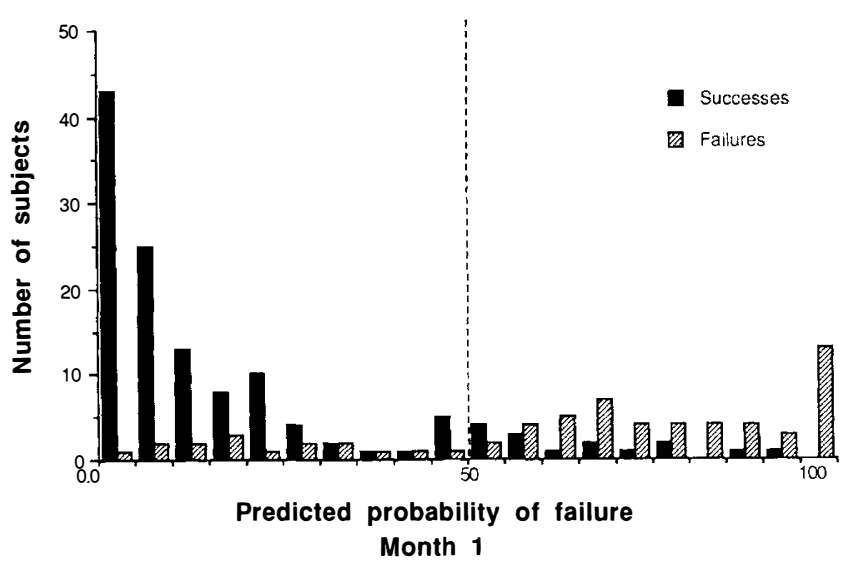

(c)

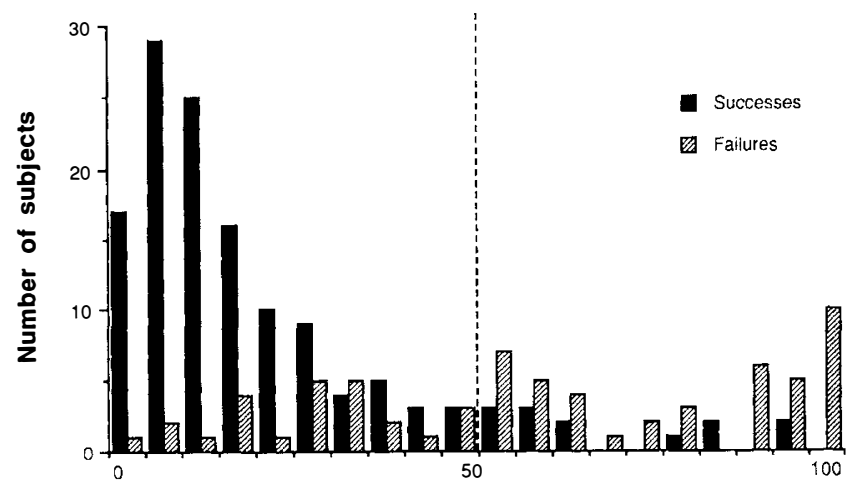

Predicted probability of failure (\%) Week 2

(b)

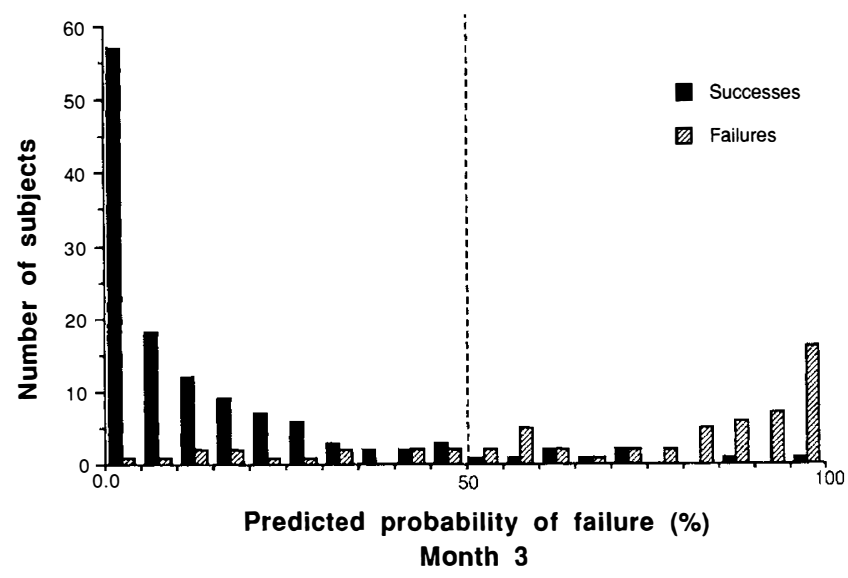

(d)

Fig. 2. Histograms of surgical outcome against predicted probability of failure at: (a) I day, (b) 2 weeks, (c) 1 month and (d) 3 months post-operatively.

diction for outcome. The accuracy for success gives the probability of correctly classifying a successful case. Thus of all the successful cases on post-operative day $1,92.6 \%$ will be correctly predicted as successes.

The reliability of prediction for success is the likelihood of a prediction of success being correct. Therefore, having made a prediction of success on day 1 for any single case, we can be $76.4 \%$ sure that it will be successful. The accuracy and reliability of prediction for failure can be interpreted similarly.

The numbers of failures or successes plotted against predicted probability of failures (pf) are presented in Fig. 2. If $\mathrm{pf}>50 \%$, failure is likely. Results at day 1 are shown in Fig. 2a. Here pf, when equal to $50 \%$, is equiva- 
lent to an IOP of $17 \mathrm{mmHg}$. The majority of cases over this limit fail. With values below 50\%, although the majority of cases succeed, there is still a relatively large number of failures. This is also true for week 2 (Fig. 2b). By months 1 and 3 (Fig. 2c, d), however, the graphs show a much greater accuracy of prediction of both success and failure.

\section{DISCUSSION}

Definition of success varies between reported series and quoted success rates for trabeculectomy range between $67 \%$ and $94 \% .{ }^{10}$ Our results are comparable with those of other groups reviewed in the literature with similar criteria, i.e. Caucasian patients with uncomplicated primary open angle glaucoma in whom a post-operative IOP $<21 \mathrm{mmHg}$ was obtained. ${ }^{2,6.7 .11 .12}$ The seniority of the surgeon, and surgical variations such as the size of scleral flap and the position of the conjunctival incision, have also been previously assessed and not found to alter outcome. ${ }^{6}$ There is evidence that pre-operative topical medications can adversely affect outcome. ${ }^{4}$ As both the failure and success groups had comparable pre-operative medications in this study, the influence of topical medication is equal in both categories.

Lowering the IOP continues to be the aim of glaucoma management. Early trabeculectomy is now recommended, as it lowers IOP to a greater extent than medical therapy. ${ }^{13}$ It has been suggested that the IOP must be reduced to at least $40 \%$ or more of the pre-operative value in order to prevent further field loss. ${ }^{14}$ Eyes with IOPs $>21 \mathrm{mmHg}$ have been shown to sustain progressive glaucomatous damage. ${ }^{3}$ Therefore recognising patients who are at risk of surgical failure is important, as early intervention may slow or arrest disease progression. Prognostic indicators of future failure have been investigated previously, ${ }^{5}$ however, the predictive significance of early high post-operative pressures has not been positively identified. ${ }^{15}$

In this study at 2 post-operative weeks there was an $84 \%$ success rate declining to a stable value of about $68 \%$ at 1 year. On the first post-operative day those cases classified as successes on the basis of an IOP $<17 \mathrm{mmHg}$ (determined by logistic discriminant analysis) would be correctly classified with a probability of $92.6 \%$. This value, together with the reliability of prediction for success, remained high. A successful outcome may therefore be accurately predicted on the basis of post-operative IOPs at any time post-operatively. Accuracy of prediction of failure based on IOP $\geqslant 17 \mathrm{mmHg}$ at day 1 increases with time and intervening IOP measurements to reach $76 \%$ at 1 post-operative month with a similar reliability value. Although the accuracy of prediction of an unsuccessful outcome on the basis of IOP is less than that of a successful outcome, this study shows that a high IOP in the early post-operative period is associated with subsequent failure and is therefore of predictive value.

Previous studies have indicated that when the procedure has failed, it does so early, almost always with 1 year. ${ }^{16} \mathrm{We}$ suggest that failure can be predicted in the majority of cases within the first post-operative month, with increasing confidence of prediction during subsequent months following surgery.

In conclusion, a successful outcome following trabeculectomy in terms of normalisation of IOP can be accurately predicted on the basis of a low IOP $(<17 \mathrm{mmHg})$ on the first post-operative day. A prediction of failure increases in accuracy with time and subsequently recorded IOPs, such that a $76 \%$ accurate prediction of failure can be made at 1 post-operative month. A high initial post-operative IOP is an indicator that the procedure is more likely to fail; therefore these patients should be reviewed carefully in the post-operative period so that medication or surgery can be initiated sooner rather than later.

Key words: Glaucoma, Glaucoma surgery, Intraocular pressure, Outcome, Trabeculectomy.

\section{REFERENCES}

1. Cairns TE. Trabeculectomy: preliminary report of a new method. Am J Ophthalmol 1968;66:673-9.

2. Watson P. Trabeculectomy: a modified ab externo technique. Ann Ophthalmol 1970;2:199-205.

3. Mao LK, Stewart WC, Shields MB. Correlation between intraocular pressure control and progressive glaucomatous damage in primary open-angle glaucoma. Am J Ophthalmol 1991;111:51-5.

4. Lavin MJ, Wormald RPL, Migdal CS, Hitchings RA. The influence of prior therapy on the success of trabeculectomy. Arch Ophthalmol 1990;108:1543-8.

5. Stewart WC, Shields MB, Miller KN, Blasini M, Sutherland SE. Early postoperative prognostic indicators following trabeculectomy. Ophthalmic Surg 1991;22:23-6.

6. Morrell AJ, Searle AET, O'Neill EC. Trabeculectomy as an introduction to intraocular surgery in an ophthalmic training program. Ophthalmic Surg 1989;20:557-60.

7. Watson PG, Jakeman C, Ozturk M, Barnett MG, Barnett F, Khaw KT. The complications of trabeculectomy; a 20-year follow-up. Eye 1990;4:425-38.

8. Kaplan EL, Meier P. Nonparametric estimation from incomplete observations. J Am Stat Assoc 1958:53:457-81.

9. Armitage P, Berry G. Statistical methods in medical research. 2nd edn. Oxford: Blackwell Scientific, 1987: 334-41.

10. Skuta GL, Parrish RK. Wound healing in glaucoma filtering surgery. Surv Ophthalmol 1987;32:149-70.

11. Akafo LK, Goulstine DB, Rosenthal AR. Long-term post trabeculectomy intraocular pressures. Acta Ophthalmol (Copenh) 1992;70:312-6.

12. Mills KB. Trabeculectomy: a retrospective long-term follow-up of 444 cases. Br J Ophthalmol 1981;65:790-95.

13. Jay JL. Rational choice of therapy in primary open angle glaucoma. Eye 1992;6:243-7.

14. Guigui A, Saraux H, Pelosse B. Trabeculectomy: long term retrospective study. J Fr Ophthalmol 1987;10:9-13.

15. Yablonski ME, Wood SE. Relationship between post-operative intraocular pressure and success of trabeculectomy. Invest Ophthalmol Vis Sci 1993;34:734.

16. Ridgway A. Trabeculectomy; a follow up study. Br J Ophthalmol 1974;58:680-6. 